\title{
Development of predictive force models for oblique cutting of mild carbon steel (CS1030) incorporating tool flank wear
}

Tertsegha IPILAKYAA

DOI: 10.30464/jmee.2019.3.4.295

Cite this article as:

Ipilakyaa T. Development of predictive force models for oblique cutting of mild carbon steel (CS1030)

incorporating tool flank wear. Journal of Mechanical and Energy Engineering, Vol. 3(43), No. 4, 2019, pp. 295-300.

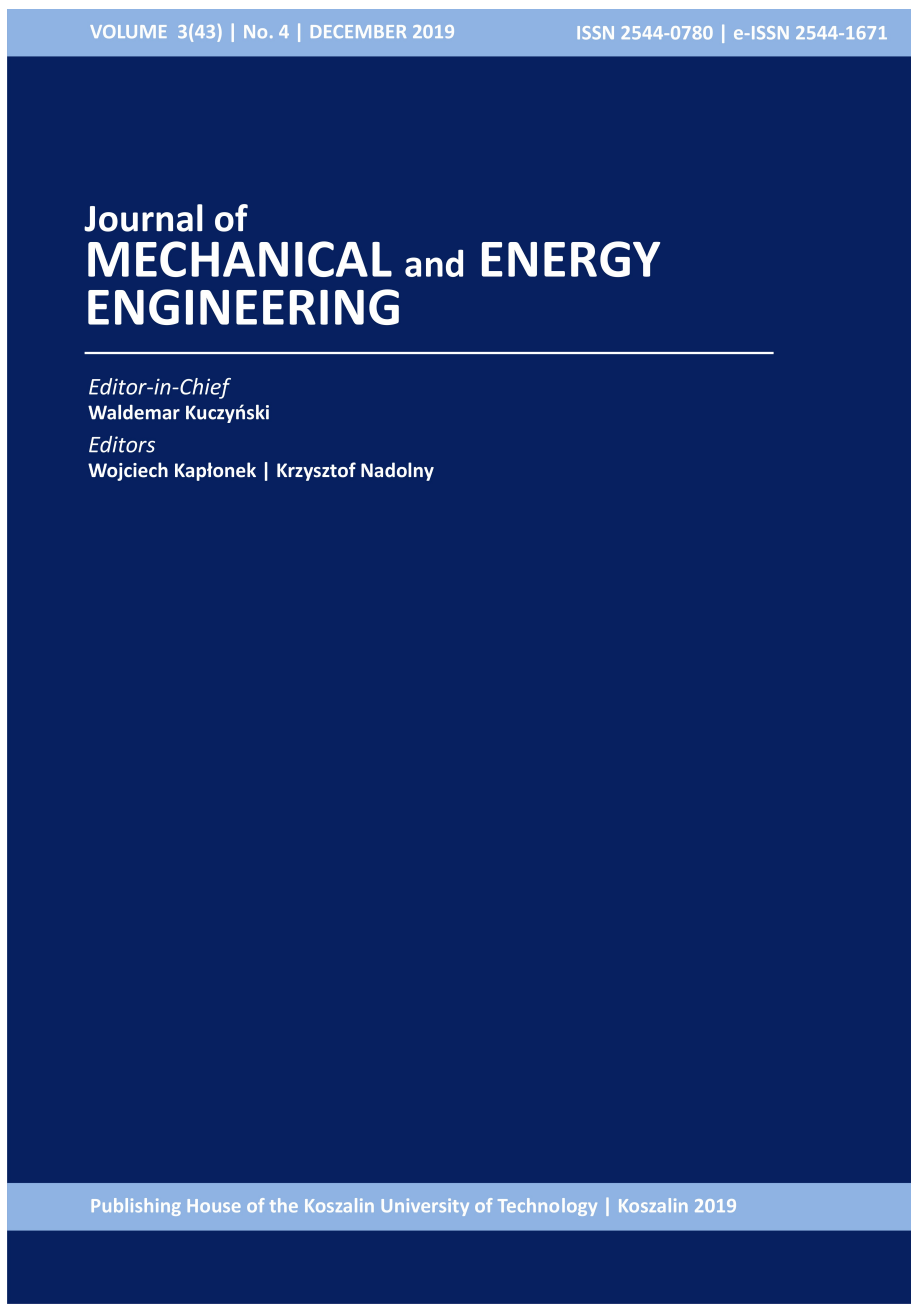

Journal of Mechanical and Energy

Engineering

Website: jmee.tu.koszalin.pl

ISSN (Print): 2544-0780

ISSN (Online): 2544-1671

Volume: 3(43)

Number: 4

Year: 2019

Pages: 295-300

Article Info:

Received 14 January 2020

Accepted 21 January 2020

\section{Open Access}

This article is distributed under the terms of the Creative Commons Attribution 4.0 (CC BY 4.0) International License (http://creativecommons.org/licenses/by/4.0/), which permits unrestricted use, distribution, and reproduction in any medium, provided you give appropriate credit to the original author(s) and the source, provide a link to the Creative Commons license, and indicate if changes were made. 


\title{
DEVELOPMENT OF PREDICTIVE FORCE MODELS FOR OBLIQUE CUTTING OF MILD CARBON STEEL (CS1030) INCORPORATING TOOL FLANK WEAR
}

\author{
Tertsegha IPILAKYAA ${ }^{1 *}$ \\ 1* College of Engineering, Department of Mechanical Engineering, Federal University of Agriculture, \\ Makurdi. P.M.B. 2373,Makurdi, Benue State- Nigeria. e-mail: ipilakyaa@yahoo.com
}

(Received 14 January 2020, Accepted 21 January 2020)

\begin{abstract}
Predictive force models for oblique metal cutting incorporating tool flank wear was carried out using a CNC lathe machine to turn mild carbon steel CS1030. The developed models are based on the fundamental mechanics of orthogonal cutting process, in which inclination angle is $0^{\circ}$. Workpieces were Cylindrical with wall thickness of $3 \mathrm{~mm}$ and diameter of $100 \mathrm{~mm}$. Cut thickness levels were $0.1,0.17,0.24$ and $0.31 \mathrm{~mm}$; cutting speeds were 100,150 and $200 \mathrm{~m} / \mathrm{min}$; tool rake angle levels were $-5,0$ and $5^{\circ}$. wearland sizes were selected as $0,0.2,0.4,0.6 \mathrm{~mm}$, where wearland size " $0 \mathrm{~mm}$ " represents sharp tool. Results of the study indicate that tool flank wear has significant effect on oblique cutting forces. The oblique cutting forces were found to increase linearly with tool flank wear due to rubbing or ploughing forces in the wearland. The results also show that, the measured experimental oblique forces (power force, $F_{c m}$ thrust force $F_{t m}$ and rubbing force $F_{r m}$ ) agreed with the predicted (power force $F_{c}$ thrust force $F_{t}$, and rubbing force $F_{r}$ ) values under the corresponding cutting conditions. It is evident from the plots that the models give an excellent prediction of the cutting forces during oblique cutting.
\end{abstract}

Keywords: oblique cutting; tool flank wear; machining; cutting force models

\section{INTRODUCTION}

The need to understand and model the metal cutting process is driven by a number of intimately woven technological requirements. Chief among them are the need to minimize vibration and to achieve the required quality of the machined part. From the machine tool designer's standpoint, modelling of cutting forces is required to ascertain the magnitude of the loads in order to generate appropriate designs [1].

Cutting tools are insistently subject to pressure and opposing stresses during cutting while machining metallic and non-metallic materials. Cutting performance parameters such as surface accuracy, tool wear, tool breakage, cutting temperature, self-excited and forced vibrations correlate strongly with cutting forces [2]. Cutting forces influence the deformation of the work piece machined, its dimensional accuracy and chip formation. More clearly, the cutting force is one of the principal factors that should be known in the metal cutting operations [3].
On the basis of the angular relationship between the cutting velocity vector and the cutting edge of the tool, different machining processes can be classified into two categories, namely: (i) the orthogonal cutting process; and (ii) the oblique cutting process [4].

Although the idealized orthogonal process (Figure 1) is a close approximation to many actual machining operations, it is clear that chip-formation process occurring at the cutting edges of most tools could be modeled more accurately by an oblique model in which the cutting edge is inclined to the cutting velocity.

\section{OBLIQUE CUTTING ANALYSIS}

In oblique cutting, an additional cutting variable and inclination angle needs to be introduced. The inclination angle plays a major role in controlling the chip flow direction and the resultant cutting force. From the force and deformation considerations and allowing for the 'collinearity conditions', the following equations have been developed [5]: 


$$
\begin{gathered}
F_{c S}=\frac{\tau b t}{\sin \phi_{n}} \cdot \frac{\cos \left(\beta_{n}-\gamma_{n}\right)+\tan i \cdot \tan \eta_{c} \cdot \sin \beta_{n}}{\sqrt{\cos ^{2}\left(\phi_{n}+\beta_{n}-\gamma_{n}\right)+\tan ^{2} \eta_{c} \cdot \sin ^{2} \beta_{n}}}, \\
F_{t s}=\frac{\tau b t}{\sin \phi_{n} \cos i} \cdot \frac{\sin \left(\beta_{n}-\gamma_{n}\right)}{\sqrt{\cos ^{2}\left(\phi_{n}+\beta_{n}-\gamma_{n}\right)+\tan ^{2} \eta_{c} \cdot \sin ^{2} \beta_{n}}} \\
F_{r s}=\frac{\tau b t}{\sin \phi_{n}} \cdot \frac{\cos \left(\beta_{n}-\gamma_{n}\right) \cdot \tan i-\tan \eta_{c} \cdot \sin \beta_{n}}{\sqrt{\cos ^{2}\left(\phi_{n}+\beta_{n}-\gamma_{n}\right)+\tan ^{2} \eta_{c} \cdot \sin ^{2} \beta_{n}}}
\end{gathered}
$$

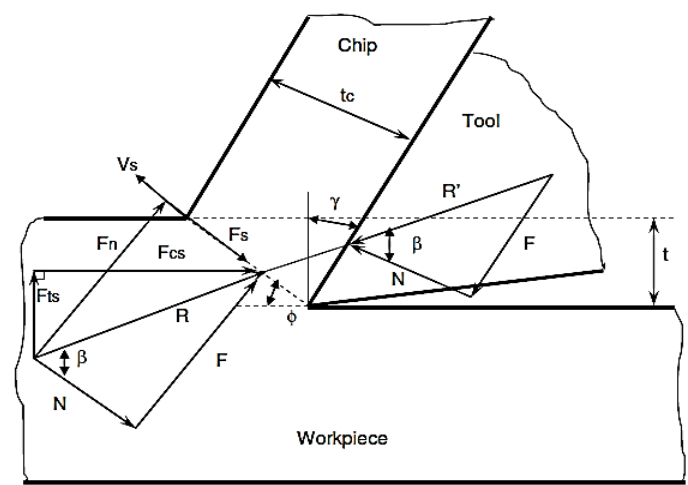

Fig. 1. Model of chip formation in orthogonal cutting for a 'sharp' tool

The shear angle and friction angle are respectively given by:

$$
\begin{aligned}
\tan \phi_{n} & =\frac{r_{l} \cdot\left(\frac{\cos \eta_{c}}{\cos i}\right) \cdot \cos \gamma_{n}}{1-r \cdot\left(\frac{\cos \eta_{c}}{\cos i}\right) \cdot \sin \gamma_{n}}, \\
\tan \beta_{n} & =\tan \beta \cdot \cos \eta_{c} .
\end{aligned}
$$

The co-linearity condition provides a means of relating the forces and velocities in oblique cutting. The condition assumes the friction force on the rake face is collinear to the chip velocity direction and shear force in the shear plane is collinear to the shear velocity direction. When the co-linearity conditions are satisfied the following equation must be met to find the chip flow angle $\eta_{c}$ [6-7]:

$$
\tan \left(\phi_{n}+\beta_{n}\right)=\frac{\tan i \cdot \cos \gamma_{n}}{\tan \eta_{c}-\sin \gamma_{n} \cdot \tan i} .
$$

From the above equations, the cutting forces can be predicted by the basic cutting quantities $\phi_{n}$ (degree), $\beta_{n}$ (degree), $\tau\left(\mathrm{N} / \mathrm{mm}^{2}\right)$ and $\eta_{c}$ (degree), for the given cutting conditions, $\gamma_{n}$ (degree), $b(\mathrm{~mm}), t$ (mm) and $i$ (degree).

Great attention has been paid to oblique cutting by a number of researchers all around the world, because many practical machining processes are actually examples of oblique cutting, and numerous research papers have been published [8-10].

In practical cutting processes, tool wear is a common phenomenon. A number of important studies have been reported on developing the relationship between tool wear and cutting forces and power in milling operations using the 'mechanistic' approach [11-15].
In early studies by Kobayashi and Thomsen [16] the friction on the worn flank of cutting tools has been experimentally studied. They found that plastic flow occurs in the work-piece beneath the tool flank. It was also found that the deformation in the primary shear zone and the friction condition on the rake face remain largely unaffected by changes at the tool flank. Okashi and Sata [17] have also studied the friction phenomenon on the flank of a cutting tool. A linear relationship of cutting force components with the width of flank wear has been observed. Zorev, [18] also noted this linear relationship. But there is no further analysis on the phenomenon observed.

The cutting forces are decided by practical cutting variables. If tool wears out at the flank, the friction force will increase and affect the cutting force components $\left(F_{x}, F_{y}, F_{z}\right)$. An equation between tool wear and cutting forces needs be developed to predict the cutting force. A cutting force model needs to be general and to suit different cutting conditions. The present study addresses this gap. An investigation has been performed to determine the effect of flank wear on the cutting process.

\section{EXPERIMENTAL SETUP}

The oblique machining tests were carried out using a CNC lathe. The workpiece was mild carbon steel, CS1030, with chemical composition of $0.3 \% \mathrm{C}, 0.6 \%$ $\mathrm{Mn}, 0.04 \% \mathrm{P}$ and $0.05 \% \mathrm{~S}$. The tensile strength of the material is $463.7 \mathrm{MPa}$ and hardness is $126 \mathrm{BHN}$. Cylindrical workpieces were prepared with a wall thickness of $3 \mathrm{~mm}$ and machined from one end. The cutting tools used were grade TP20 carbide flat-top inserts with $8 \mu \mathrm{m}$ TiN coating.

Three levels of cut thickness $(0.1,0.17$ and $0.24 \mathrm{~mm}$ ) were tested at two levels of cutting speed (100 and $200 \mathrm{~m} / \mathrm{min}$ ) and three levels of normal rake angle $(-5,0,5)$. In addition, three levels of wear land size including 'sharp' tools were selected. These were $0.2,0.4$ and $0.6 \mathrm{~mm}$. The wear land sizes were selected according to ISO3685 [19] and some were higher than the recommended value in order to study the force pattern for tool condition monitoring in future investigations. Thus a total of 144 tests with 4 specially made tool holders and 16 inserts were conducted.

The wear land was artificially made on the cutting tools by a lapping process using an abrasive grinder and checked frequently under a shadowgraph projector for its size. Care was taken to ensure that the final artificial wear land was within a tolerance of $\pm 3 \%$ of its specified size. The specified sizes were used in the qualitative analysis but the actual sizes were used in the regression analysis for the basic cutting quantities database.

The cutting and thrust force components were measured using a three-component piezoelectric 
dynamometer which was mounted on the tool post (magazine) with a specially made rest. The cutting tool was held on the top of the dynamometer. The induced cutting and thrust force signals were processed and amplified by two charge amplifiers. The amplified signals were then recorded for further processing by a computer through an analog-to-digital (A/D) converter card and data acquisition software. The final results were taken from the average of 20 force samples in the steady cutting stage.

For each combination of the cutting speeds, wear land sizes and rake angles, a linear regression analysis of the measured cutting and thrust force components $F_{c m}$ and $F_{t m}$ with respect to the cut thickness $\mathrm{t}$ was carried out. The force intercept in the regression analysis was determined as the "edge force" component for "sharp" tools or the edge and wear land force for tools with a wear land. In doing so, it was assumed that the flank wear did not affect the forces required for chip formation in the shear zone and at the tool-chip interface. By comparing the intercept with that of the respective sharp tool, the wear land force component for each test (with a wear land) was evaluated for further analysis. The friction angle $\beta$ and shear stress $\tau$ for each cut were finally calculated using equations (4) and (5) respectively, after the edge force (or edge and wear land force) has been removed from the measured forces.

\section{RESULTS AND DISCUSSION}

\subsection{Oblique cutting model with tool flank wear}

The general trends of the predicted cutting forces (power, thrust and rubbing) with respect to the cut thickness and wearland size are shown in Figures 2 and 3 respectively. The predicted forces are plotted with dotted lines while the experimental forces are plotted with solid lines. The predicted forces are evaluated using equations (7), (8) and (9), and the experimentally determined basic cutting quantity database in Table 1.

Mathematically, the overall cutting power $\left(F_{c}\right)$, thrust force $\left(F_{t}\right)$ and rubbing force $\left(F_{r}\right)$ models have been experimentally found to be:

$$
\begin{gathered}
F_{c}=K_{c s} b t+C_{c e} b+\frac{C_{c w} b \cdot V B}{\cos i} \\
F_{t}=K_{t s} b t+\frac{C_{t e} b}{\cos i}+\frac{C_{t w} b \cdot V B}{\cos i} \\
F_{r}=K_{r s} b t+C_{c e} b \cdot \tan i
\end{gathered}
$$

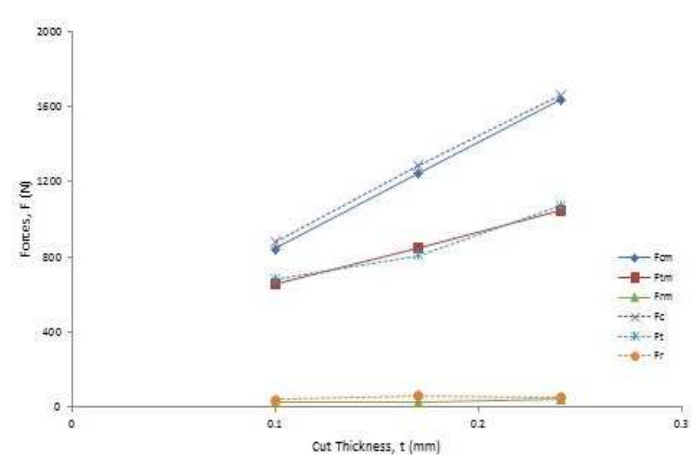

Fig. 2. Predicted and experimental forces versus cut thickness in oblique cutting at $v=100 \mathrm{~m} / \mathrm{min}$, $i=5^{\circ}, \gamma_{n}=0^{\circ}$

Tab. 1. Models for basic cutting parameters

\begin{tabular}{cc}
\hline Cutting parameter & Modeled equation \\
\hline Frictional angle, $\beta\left(^{\circ}\right)$ & $\beta=36.53+0.41 \gamma-0.07 \mathrm{~V}$ \\
\hline Shear stress, $\tau\left(\mathrm{N} / \mathrm{mm}^{2}\right)$ & $\tau=417.52+4.39 \gamma+0.35 \mathrm{~V}$ \\
\hline Chip length ratio, $r_{l}$ & $r_{l}=0.327+0.004 \gamma$ \\
\hline $\begin{array}{c}\text { Edge force coefficients } \\
C_{c e} \text { and } C_{t e}(\mathrm{~N} / \mathrm{mm})\end{array}$ & $C_{c e}=74.2$ \\
\hline $\begin{array}{c}\text { Wearland force coefficients } \\
C_{c w} \text { and } C_{t w}\left(\mathrm{~N} / \mathrm{mm}^{2}\right)\end{array}$ & $C_{t e}=89.3$ \\
\hline
\end{tabular}




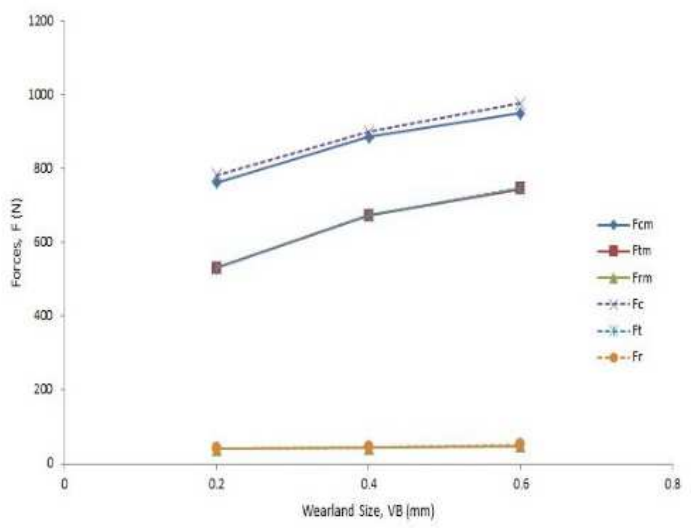

Fig. 3. Predicted and experimental forces versus wearland in oblique cutting at $v=100 \mathrm{~m} / \mathrm{min}, i=5^{\circ}$, $y_{n}=5^{\circ}$ and $t=0.1 \mathrm{~mm}$

Figures 2 and 3 show that all the three predicted force components $F_{c}, F_{t}$ and $F_{r}$, and the three experimentally measured force components $F_{c m}, F_{t m}$ and $F_{r m}$ are shown to increase linearly with cut thickness $t$, as expected.

Qualitatively, the measured experimental forces agreed with the predicted values very well under the corresponding cutting conditions. It is evident from the figures that the models give an excellent prediction of the cutting forces in oblique cutting.

The graphs indicate that the modelled forces are in good correlation with the experimental data. It has also been found that cutting forces increase linearly with wear land size. Plots of cutting forces versus other variables under different conditions show that the predicted trends of the cutting forces are consistent with those reported in the literature and from the mechanics of cutting analysis. Thus, the generality and plausibility of the proposed cutting force models have been amply demonstrated.

\subsection{Model Validation}

The proposed predictive force models for oblique cutting with tool flank wear have been verified for their plausibility and predictive capability. The models verification is conducted by comparing both qualitatively and quantitatively the predicted forces with the corresponding experimental results. For a quantitative assessment of the predictive capability of the oblique cutting force models, the percentage deviations of the model predicted values with respect to the corresponding experimental data have been analyzed. The analysis show that the model predictions yield a maximum percentage deviation of $2.39 \%$ for power force, $0.25 \%$ for thrust force and $5.34 \%$ for radial force, while the corresponding percentage standard deviations are $2.2 \%, 0.8 \%$ and $11.62 \%$ respectively.
The oblique cutting models show excellent correlation between predicted and measured values.

\section{CONCLUSIONS}

Tool flank wear has significant effect on the overall cutting force models for oblique cutting as there is an increase in the cutting forces when tool flank wear is present. The increase is as a result of rubbing or ploughing forces in the wearland.

\section{Acknowledgements}

The authors wish to express gratitude to the National Agency for Science and Engineering in Nigeria (NASENI) for technical support and provision of equipment for this research.

\section{References}

1. Ehmann K.F., Kapoor S.G., Devor R.E. (2014). Machining Process Modelling: A Review. Journal of Manufacturing Science and Engineering. Vol. 119, No. 1, pp. 655-663.

2. Kamely M.A., Noordin M.Y. (2011): The Impact of Cutting Tool Materials on Cutting Force. World Academy of Science, Engineering and Technology. Vol. 51, pp. $103-114$.

3. Dayong Y., Zhenping W., Peijie X., Longsheng L. (2018). Rake Angle Effect on a Machined Surface in Orthogonal Cutting of Graphite/Polymer Composites. Journal of Advances in Materials Science and Engineering. Vol. 2, No. 1, pp. 222-227.

4. Roger E. H., Angela M. L., Ahmed K. (2014): Effects of Cutting Parameters on Cutting Forces and Surface Quality of Black Spruce Cants. European Journal of Wood Production, Vol. 72, pp. 107-116.

5. Takashi M., Shoichi T. (2017). Cutting Force Model in Milling with Cutter Runout. 16th CIRP Conference on Modelling of Machining Operations. Elsevier, pp. 566 - 571.

6. Jianbo S., Naohiko S., Kentaro I., Kanako H. (2013). Force Analysis of Orthogonal Cutting of Bovine Cortical Bone. Machining Science and Technology: An International Journal. Vol. 17, No. 4, pp. 637-649.

7. Coelho, R.T. Braghini, A. Valente C.M.O, Medalha G.C. (2003). Experimental Evaluation of Cutting Force Parameters Applying Mechanistic Model in Orthogonal Milling. Journal of the Brazilian Society of Mechanical Science and Engineering. Vol. 25, No. 3, pp. 1-23.

8. Guicai, Z., Changsheng, G. (2015). Modeling of Cutting Force Distribution on Tool Edge in Turning Process. Procedia Manufacturing. 43rd Proceedings of the North American Manufacturing Research Institution of SME. Vol. 1, No. 1, pp. 454-465.

9. Huangwen, X., Jianming, D., Yuzhen, C., Huaiyuan, L., Zhicheng, S. and Jing, X. (2018). The Relationships between Cutting Parameters, Tool Wear, Cutting Force and Vibration. Journal of Advances in Mechanical Engineering, Vol. 10, No. 1, pp. 1-14.

10. Harshit K. D., Harit K. R. (2010). Modelling of Cutting Forces as a Function of Cutting Parameters in Milling Process using Regression Analysis and Artificial Neural Network. International Journal of Machining and Machinability of Materials, Vol. 8, Nos. 1/2, pp. 198-208

11. Juneja, B.L., Sekhon G.S. (1987). Fundamentals of Metal Cutting and Machine Tools, Wiley Eastern Ltd., New Delhi. 
12. Armarego, E.J.A. and Brown, R.H. (1963). The Influence of Rake Angle on the Forces in Machining. Machine Shop and Metal Working, Australia.

13. Armarego, E.J.A. and Brown, R.H. (1969): The Machining of Metals. New Jersey, Prentice Hall.

14. Armarego, E.J.A. (1982). Practical Implications of Classical Thin Shear Zone Analysis. In UNESCO/CIRP Seminar on Manufacturing Tech., Singapore.

15. Aksu, B.,Çelebi, C., Budak E. (2017). An Experimental Investigation of Oblique Cutting Mechanics. Journal of Machining Science and Technology. Vol. 2, No. 1, pp. 3376.

16. Filippov, A.V., Filippova, E.O. (2015). Determination of Cutting Forces in Oblique Cutting. Journal of Applied Mechanics and Materials. Vol. 756, No. 1, pp. $211-215$.

17. Shamoto, E., Altintas, Y. (1999). Prediction of Shear Angle in Oblique Cutting with Maximum Shear Stress and Minimum Energy Principles. Journal of Manufacturing Science and Engineering. Vol. 5, No. 1, pp. 112-143

18. Ipilakyaa, T. D., Tuleun, L. T., Gundu, D. T. (2014) Predictive Force Models for Orthogonal Cutting Incorporating Tool Flank Wear. International Journal of Engineering and Technology. Vol. 4, No. 7, pp. 2049-3444.

19. Siddhpura, A., Paurobally, R. (2012). A Study of the Effects of Friction on Flank Wear and the Role of Friction in Tool Wear Monitoring. Australian Journal of Mechanical Engineering. Vol. 10, No. 2, pp. 141 - 155

20. Samsudeen, S.S., Rakesh, N., Nisaantha, K.N Krishnaraj, V. (2015). Study on Cutting Forces and Tool Wear during End-Milling of Ti-6al-4v Alloy 75 International Journal of Mechanical and Production Engineering. Vol. 3, No. 9, pp. 2320-2092.

21. David, W.S., Shiv, G.K. and Richard, E.D. (2000) A Worn Tool Force Model for Three-Dimensional Cutting Operations. International Journal Machine Tools and Manufacturing, Vol. 40, No. 1, pp. 1929-1950.

22. Huang, Y., Dawson, T.G. (2005). Tool Crater Wear Depth Modeling in CBN Hard Turning. Wear, Vol. 258, No. 1, pp. 1455-1461.

23. Thamizhmanii, S., Hasan, S. (2010): Relationship between Flank wear and Cutting Force on the Machining of Hard Martensitic Stainless Steel by Super Hard Tools. Proceedings of the World Congress on Engineering, Vol III WCE 2010, London, U.K.

24. Shoujin, S., Milan, B. and John P. M. (2013). Evolution of Tool Wear and its Effect on Cutting Forces During Dry Machining of Ti-6Al-4V Alloy. Journal of Engineering Manufacture, Vol. 3, No. 2, pp. 21-45.

25. ISO 3685:1993(E) (1993): Tool-Life Testing with Single-Point Turning Tools, pp. 1-48

\section{Biographical note}

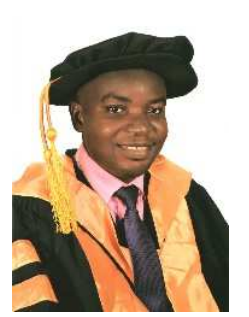

Ipilakyaa Tertsegha received his B.Eng, M.Eng and Ph.D degrees in 2004, 2010 and 2014 respectively from the University of Agriculture, Makurdi- Nigeria. Since 2012, he has been lecturing with the same University in the department of Mechanical Engineering. $\mathrm{He}$ is currently a Senior Lecturer with research interest in machine tools, design andconstruction. He is currently teaching advanced machine tool among other courses. 
